\title{
The Impact of Service Failure Controllability and Relationship Strength on Post-Complaint Consumer Behavior - An Empirical Analysis
}

\author{
Frederike von Aswege \\ RWTH Aachen University \\ vonaswege@time.rwth-aachen.de
}

\author{
Jan Kemper \\ RWTH Aachen University \\ kemper@time.rwth-aachen.de
}

\author{
Malte Brettel \\ RWTH Aachen University \\ brettel@time.rwth-aachen.de
}

\begin{abstract}
The purpose of this research is to explore the impact of service failure controllability on consumer purchase behavior and to clarify the moderating role of relationship strength. Our conceptual model posits that high levels of firm controllability are associated with negative customer reactions. In addition, we examine two opposing hypotheses discussed in literature: the "love becomes hate" and the "love is blind" effect. We base our analysis on an extensive data set provided by a leading European online retailer that includes more than 14,000 complaints and 165,000 orders. Our research emphasizes the relevance of attribution theory in the context of actual consumer behavior and confirms that high levels of firm controllability are associated with negative consumer reactions. The empirical results further show that a strong customerorganization relationship mitigates the negative effects of service failures independently of the level of firm controllability. Therefore, the "love is blind" effect is strongly supported.
\end{abstract}

\section{Introduction}

Service failures occur in every industry and pose a significant threat to companies. Despite companies always aiming for an optimized customer service experience, even the best service providers cannot prevent all failures [37, 51]. This is especially critical since service failures have been identified as a major cause for negative reactions by customers [58]. After a service failure customers are more likely to experience feelings of rage [63] and switch the service provider [43] thereby potentially leading to a decline in firm profitability [73]. Given the inevitability of service failure occurrence and the damaging consequences for companies, it is important for marketers to understand how customers interpret service failures in order to predict their subsequent responses [20]. However, despite the identified need to gain deeper insights into consumer purchase behavior following a service failure, research in this area is rather scarce [13].

Attribution theory is one theoretical foundation that helps to understand customer reactions and controllability attributions have been found to be extremely relevant in service failure contexts [65]. Controllability attributions can be defined as a customer's belief that the firm could have prevented the failure [21, 37]. Generally speaking, customers who believe that a company is responsible for the failure (high firm controllability) are likely to react negatively [13] even though there are only limited insights with regard to actual consumer behavior [65].

These negative reactions are especially critical if companies risk to lose their best customers since researchers commonly agree that good customer relationships are a competitive advantage [27]. However, the effect of relationship strength in the context of service failures is not yet fully understood [28]. While some studies conclude that good customer relationships magnify customers' negative reactions to a service failure (e.g., [50]), others find that a good relationship acts as a buffer when negative incidents happen (e.g., [37]). Therefore, it is of particular relevance to understand how controllability attributions and customer relationship strength interact. To the best of our knowledge, Grégoire and Fisher [27] were the first to investigate this relationship. Their study reveals that in situations where the customer does not perceive the company as responsible for the failure strong customer relationships mitigate negative responses. This supports the idea that customer relationship strength can act as a buffer. However, no significant results for situations where the customer blames the company for the service failure are found.

Given the lacking insights regarding the importance of controllability attributions in the context of actual consumer behavior as well as the inconclusive results on the interaction effect of controllability attributions and relationship strength, we propose the following two research questions: (1) How do controllability attributions ascribed to a service failure influence subsequent consumer purchase behavior? (2) How 
does a customer's relationship with the company moderate the effect of controllability attributions on consumer purchase behavior?

We will address these research questions by leveraging an extensive field data set. We were able to build an exclusive cooperation with one of Europe's leading e-commerce retailers operating in the fashion business in over 15 countries. Our data includes more than 14,000 complaints that were filed regarding two service failure types that differ in their level of firm controllability. In addition, we add transactional data of more than 165,000 orders and personal customer information to the data set.

By leveraging this unique data set our research contributes to the current literature in three ways. First, researchers so far have only been able to analyze the effect of controllability attributions on behavioral intentions even though it is acknowledged that the link between intentions and actual behavior is very weak [12]. We will overcome this shortcoming by utilizing field data which allows us to investigate actual consumer purchase behavior and to reliably evaluate the effect of controllability attributions. Second, when it comes to assessing customer relationship strength, most studies have relied mainly on customer surveys [29]. Lately, however, researchers call for the utilization of actual transaction-based data in this context $[54,65]$. We follow these calls and assess customer relationship strength based on the actual transaction history. Third, as explained, the interaction effect of controllability attributions and customer relationship strength has not yet been fully comprehended and calls for further investigations in this area exist [37]. We attempt to fill this gap by providing valuable insights on the importance of relationship strength in both low and high firm controllability situations.

\section{Conceptual background and hypotheses}

The conceptual framework underlying our research is based on attribution theory [33, 67] and combines this well-established theoretical foundation with insights on the importance of customer relationships [27]. Figure 1 depicts our research.

\subsection{Attribution theory and consumer behavior}

Attribution theory is concerned with understanding how people arrive at causal attributions for certain events and how they react based on these inferences $[21,67]$. Causal attributions help people to comprehend, structure, and manage themselves, their environment, and their interactions with others [65,
68]. Literature commonly distinguished between three types of attributions: locus, stability, and controllability. Since controllability is highlighted to be of great relevance in service research [65] it is the focus of our research.

Attributions of controllability refer to the degree to which a cause is thought to be volitional or not controllable $[67,68]$. High firm controllability refers to situations where the customer perceives the firm to be accountable for the service failure whereas in low firm controllability situations the service failure is perceived as beyond the control of the company $[22,37,69]$.

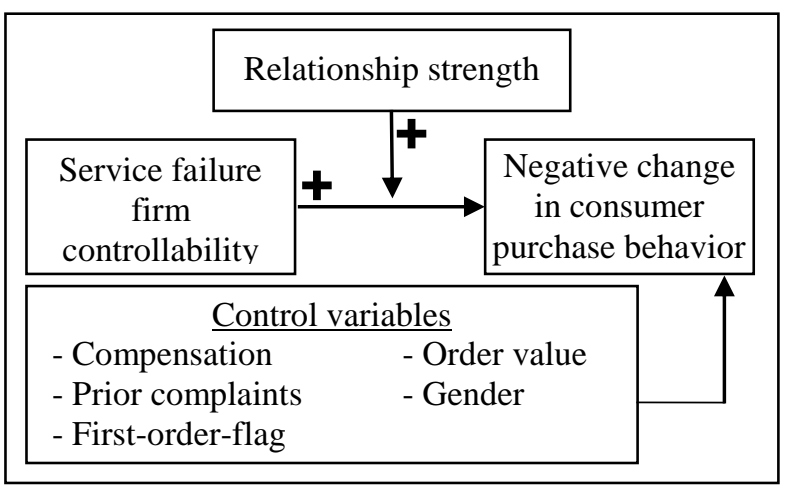

Figure 1. Conceptual framework

Researchers have found that controllability attributions affect customers' feelings and the resulting behavior in multiple ways. Folkes, Koletsky, and Graham [22] suggest that controllability influences customers' intentions to complain as well as their repurchase intention. Kaltcheva, Winsor, and Parasuraman [42] evaluate the effect of controllability on repatronage intentions, complaint intentions, and negative word-of-mouth intentions. Their results indicate that high firm controllability negatively influences customers' repatronage intentions while it is positively associated with unfavorable word-of-mouth and complaint intentions. However, the latter effect is only found for immediate complaints while still in the store and is not supported for delayed complaints. Similar results have been found by Choi and Mattila [13] who find that high firm controllability leads to lower overall satisfaction, lower repurchase intent, and lower positive word-of-mouth intentions. In line with these findings, Hess [36] hypothesizes that controllability is negatively related to repurchase intent and confirms this hypothesis. His results, however, do not support the proposed positive relationship between firm controllability and negative word-of-mouth intentions. In a meta-analysis, van Vaerenbergh et al. [65] attempt to better understand the effects of controllability. They find that attributions of controllability elicit stronger negative emotions than do 
attributions of stability. Furthermore, high firm controllability affects transaction-specific satisfaction and ultimately leads to lower levels of loyalty. Hess, Ganesan, and Klein [37] find that customers who have experienced a controllable failure expect a better recovery service in order to offset for the negative incident. Similar results were found by Folkes [20]. In addition, her analysis reveals that high controllability attributions lead to feelings of anger and a "desire to hurt the [...] business" [20:401].

Summarizing, there is agreement that high firm controllability is negatively related to customers' emotions, feelings as well as behavioral intentions. The effect of controllability on actual consumer purchase behavior, however, has not yet been comprehensively addressed [65]. Still this relationship is of significant importance as it provides insights on the validity of attribution theory in the context of actual consumer behavior, sheds light on the transferability of results found for consumer intention to actual consumer behavior, and provides valuable information to practitioners. Drawing on the summarized findings and insights from attribution theory we derive our hypothesis:

H1: Service failures characterized by high firm controllability are related to a more negative change in consumer purchase behavior than are service failures characterized by low firm controllability.

\subsection{Consumer relationships and consumer responses to service failures}

The impact of customer relationships is frequently studied in the service marketing literature [1]. Most studies use relationship quality (RQ) [16, 72] or relationship strength $(\mathrm{RS})[11,29]$ as constructs to evaluate a customer's relation with the firm. In studies working with secondary data, researchers often assess the strength of a relationship based on the customer's transactional history with a firm and the expected future $[6,11,37,55]$.

Despite some opposing findings [56], past relationship research mostly agrees that good customer relationships are beneficial for a company's performance. Good customer relationships are found to be positively associated with acquiescience and cooperation while reducing propensity to leave [53]. Additional research confirms that good customer relationships lead to higher customer retention [34, 59] and positively influence purchase behavior [39] as well as customer equity [74]. Ultimately, researchers suggest that RQ is positively related to the financial performance of a company [62] which has been supported in a business-to-business environment [5].
Nevertheless, there is a lack of studies addressing the role of customer-organization relationships in a complaint and service marketing context and existing results are still inconclusive [27]. This gap is especially surprising given the just explained benefits of good customer relationships. These benefits are at risk if a service failure occurs. Current research provides two opposing explanations for the impact of customer relationships in case of service failures.

2.2.1. Love becomes hate effect. The first explanation, also referred to as the "love becomes hate" effect, argues that good customer relationships amplify the negative emotions and reactions a customer shows after a service failure [27]. Due to the good relationship a customer has with the organization, the service failure leads to a stronger feeling of betrayal, thereby provoking more negative reactions. A customer with a less emotional or strong relationship with the company, in contrast, has lower expectations [27]. Consequently, the disappointment in case of a service failure is lower and reactions are less extreme [28]. This explanation is rooted in the group-value theory which proposes that loyal customers are more likely to experience a negative change in attitude if they feel unfairly treated $[9,47]$. As a result, customers feel a desire for revenge [66]. Similarly, the contrast effect states that great differences between past and present experiences cause extreme reactions [4, 38]. Therefore, previously committed customers with positive past experiences with the company may show more extreme reactions to a service failure.

Some researchers have found support for the "love becomes hate" effect. Goodman et al. [24] show that customer involvement with a company increases the level of dissatisfaction in case of product failure. Dawes [17] analyzes how relationship breadth, defined as "the number of different products the customer currently purchases from the focal service provider" [17:235], influences customer retention after price increases. He finds that a broader relationship is related to higher price sensitivity indicating a more negative reaction. Contrary to this conclusion, his results reveal as well that relationship tenure is associated with a higher likelihood of repatronage after a price increase. Grégoire, Tripp, and Legoux [29], too, find support for the "love becomes hate" effect. They find that there is a positive association between RQ and perceived betrayal as well as between RQ and desire to avoid the involved company. Their results further confirm that high RQ customers hold feelings of revenge for a longer time than do low RQ customers and that they are also faster in developing a desire of avoidance. Similarly, Mattila's work [50] reveals that affective commitment magnifies the negative effect of service 
failures on customers' attitudes. Still, these negative attitudes did not translate into negative behavioral intentions.

2.2.2. Love is blind effect. The second explanation, referred to as the "love is blind" effect, implies that a good customer relationship acts as a buffer in bad times and, therefore, diminishes customers' negative reactions to service failures [27]. This effect is based on assimilation bias theory [9], cognitive dissonance theory [19], and the reverse negativity effect [2]. Assimilation bias theory argues that people react in ways that are consistent with their prior attitudes [9]. A committed customer is, thus, more likely to keep patronizing a company after a service failure. The theory on cognitive dissonance states that individuals experience mental stress when they hold contrasting beliefs [19]. Consequently, they try to avoid drawing conclusions that do not correspond with their previously held beliefs. Another widely supported theory in consumer psychology is the negativity effect which argues that people put more weight on negative information than on positive information [35, 60]. Previous research in this field, however, has found that customers committed to a certain brand reinterpret negative information and instead put more weight on positive information provided [2, 3].

Applying these theoretical foundations to our research area, we can infer that customers with a strong relationship may be more likely to ignore or devaluate a service failure since these events contradict their previous attitudes towards and experiences with a service provider. Consequently, Berry [7] proposes that good customer relationships lead to higher tolerance of failures. Hess, Ganesan, and Klein [37] find that after a service failure customers with a strong relationship are more likely to believe in relationship continuity, have lower recovery expectations, and are more satisfied. Hur and Jang [41] confirm as well that customer relationships are associated with recovery satisfaction. Furthermore, results of two experiments conducted by Mattila [49] suggest that a close customer relationship mitigates the negative effects of poor service recovery on loyalty, implying that customers with a strong relationship are more willing to forgive the service provider. This positive buffer effect has also been confirmed with regard to trust and commitment [64]. Knox and van Oest [46] further found that a customer's relationship, measured as number of past purchases, mitigates negative reactions after a complaint.

2.2.3. Linking relationship strength and controllability attributions. In 2006, Grégoire and Fisher [27] combine the existing knowledge on controllability attributions and customer relationships.
They argue that in low firm controllability settings customers are more willing to forgive a company for its service failure and that this effect is even stronger for high RQ customers because they can more easily reinterpret a service failure that is beyond the control of the firm. The opposite is hypothesized in case of service failures characterized by high firm controllability. In these situations high RQ customers are expected to express more negative reactions due to the mismatch with previous experiences as well as greater perceived betrayal. As outcome variable they use desire for retaliation which is shown to be positively related to negative word-of-mouth, thirdparty complaining, and patronage intentions. Results indicate that in a low controllability setting high RQ customers express a significantly lower desire for retaliation than do low RQ customers. Therefore, the "love is blind" effect is supported in situations where the customer does not blame the company for the service failure. In high controllability conditions, in contrast, high RQ customers directionally express a higher desire for retaliation. This is in line with the proposed "love becomes hate" hypothesis. However, a post-analysis reveals that the difference in desire for retaliation between high and low RQ customers in a high controllability setting is not significant. In 2008, Grégoire and Fisher [28] again hypothesize a "love becomes hate" effect and find that high RQ customers feel a stronger sense of betrayal. In this paper they include firm's blame, a construct measured along the same items as firm controllability, as a control only. Nonetheless, they emphasize the importance of firm controllability and call for further research in this area.

We address their call and attempt to further investigate the interaction effect of firm controllability and customer relationship but in the context of actual consumer behavior. Following De Cannière, De Pelsmacker, and Geuens [11] we investigate the moderating effect of RS on consumer behavior.

H2: In low controllability situations, high $R S$ customers react less negatively to service failures than do low RS customers, thereby supporting the "love is blind" effect.

H3: In high controllability situations, high $R S$ customers react more negatively to service failures than do low RS customers, thereby supporting the "love becomes hate" effect.

\section{Research method}

\subsection{Data}

We were able to obtain a unique data set including actual complaint information and related transaction 
data. Our exclusive cooperation partner is a leading European online-only retailer operating in the fashion business. The obtained data set covers 14 European markets and a core period of 16 months from September 2015 to December 2016.

If a service failure occurs, a customer has multiple channels to contact and to complain to the retailer be it via phone, mail, app, or website interface. If a customer contacts the retailer, the responsible customer care employee not only handles the case but also categorizes it in the company's system into one of over 250 different contact reasons. This way, every customer contact is categorized on a very granular level and is further connected to a customer profile as well as to a certain order or product. As a consequence, very detailed knowledge on when, why, and how a customer complained is available to the retailer.

Based on this extensive database we selected two complaint reasons that differ in perceived firm controllability. In total, we include 14,117 complaints filed by distinct customers in our analysis. The low firm controllability scenario includes customers that complain because a certain product they received did not match the usual size specifications, meaning that a product was either smaller or larger than expected based on its size tag. The high firm controllability scenario includes customers that complain because the retailer has sent a product in a different size than ordered. The result for the customer is the same in both cases, i.e., a product that does not fit. However, in the low controllability scenario the customer perceives the manufacturer as responsible for the not fitting product, while in the high controllability scenario the retailer is seen as responsible since a wrong product has been sent. We conducted a pre-test to ensure a substantial difference in firm controllability. The pre-test follows the measures developed by Hess, Ganesan, and Klein [37] and is based on a 7-point Likert scale. The pre-test respondents agreed that the chosen failure scenarios differ in controllability $(6.8,3.5, t(20)=8.6896$, $p<.001)$. As severity has been found to have considerable impact in service failure situations [36, $45]$, we further verified that there is no significant difference in perceived severity $(4.6,5.2, t(20)=-1.303$, $p>.2)$.

\subsection{Measures}

We define our outcome variable change in consumer purchase behavior as percentage change in customer spending after the complaint [25, 32]. We take the deviation between a customer's total expenditures six months before and after the complaint and divide it by the expenditures before the complaint.
For our predictor variable firm controllability we consider all complaints of the two selected types that were filed between March and June 2016. We code the complaint cases in our data set according to the pre-test results as dummy variables (low firm controllability as 0 and high firm controllability as 1) with 1,978 coded as low controllability cases and 12,139 being coded as high controllability cases. Though the number of cases for each complaint type differs we have a sufficiently large sample for the analysis.

Following Pick et al. [55] and Hess, Ganesan, and Klein [37], we conceptualize RS as the total number of orders during a customer's lifetime before the complaint. For this variable we went beyond the time frame of 16 months between September 2015 and December 2016 and included all orders a customer had ever placed with the retailer. In total, we considered 165,152 orders for this variable. We decided to not use relationship duration since it would overestimate the relationship strength of customers with a long but inactive purchase history [11].

We include multiple controls in our model that could explain variance in changes in consumer purchase behavior. To account for the significant impact of a company's service recovery efforts $[10,51]$ we include compensation defined as the percentage amount of the voucher offered. If no voucher is offered the percentage value is coded as 0 . The next covariate prior complaints reflects a customer's prior experience with the retailer $[27,61]$ and is defined as the absolute number of customer care contacts in the six months before the relevant complaint. Since importance of product has been found to be a relevant variable in the complaint management context [40], we add order value as a covariate to approximate the importance of the order. Further, we control for first-time customers (i.e., customers who have placed their first order with the retailer and directly experienced a reason to complain) as these customers may be more dissatisfied after the service failure [48]. The variable first-orderflag is coded 1 for first-time customers. The covariate gender is included due to its supported relevance [28, 52 ] and is coded as a dummy with 1 for female.

\subsection{Regression procedure}

We investigate the proposed relationships by applying an ordinary least square log-log-regression which follows methodologically related research [57] and allows for a practical interpretation of the results.

We standardize all continuous predictor variables. We use the Durbin-Watson test to ensure that the residuals are independent and there is no issue with autocorrelation. The Durbin-Watson statistic is close to 
Table 1. Descriptive statistics for continous variables

\begin{tabular}{lccc}
\hline Variables & & M & SD \\
\cline { 1 - 1 } \cline { 4 - 4 } Change in consumer purchase & & -0.04 & 1.79 \\
behavior & & 11.70 & 17.79 \\
Relationship strength & & 0.07 & 0.08 \\
Compensation & & 119.54 & 133.06 \\
Order value (in EUR) & & 4.02 & 4.27 \\
\hline
\end{tabular}

Total number of observations 14,117; M=Mean, SD=Standard deviation

2 and non-significant for both models, thus, there is no problem with autocorrelation. All correlation coefficients are well below the threshold of 0.8 [44].

For each predictor variable we calculate the variance inflation factor (VIF) and all VIFs are below the recommended threshold of 10 [31]. We can, therefore, conclude that we do not have problems with multicollinearity in our data set. By applying the Breusch-Pagan-test [8] and the NCV test we check for heteroscedasticity in our models. Both tests yield significant results $(\mathrm{p}<.001)$ so that we need to reject the null hypothesis of homoscedasticity. Following other publications [14, 30, 55], we use Huber-White robust standard errors in our models to account for heteroscedasticity which does not affect the significance levels of our analyses. Table 1 displays the descriptive statistics for the continuous variables.

\section{Results}

In a first step we test our main hypothesis that there is a significant relation between firm controllability and subsequent consumer purchase behavior. To this end, we use firm controllability as main predictor variable and change in consumer purchase behavior as outcome variable. We use the following model:

$$
\begin{aligned}
& \log \left(\text { PURCHANGE }_{i}=\beta_{0}+\beta_{1} \cdot \text { CTRL }_{\mathrm{i}}\right. \\
&+\beta_{2} \cdot \log (\text { COMP })_{\mathrm{i}}+\beta_{3} \cdot \log (\text { ORDVAL })_{\mathrm{i}} \\
&+\beta_{4} \cdot \log (\text { PRIORCOMPL })_{\mathrm{i}} \\
&+\beta_{5} \cdot \text { FIRSTORD }_{\mathrm{i}} \\
&+\beta_{6} \cdot \text { GEND }_{\mathrm{i}}+\varepsilon_{\mathrm{i}}
\end{aligned}
$$

where $\mathrm{i}(=1, \ldots, 14117)$ stands for the individual complaining customer. The outcome variable PURCHANGE is the change in customer expenditures after the complaint in percent. CTRL represents the predictor variable firm controllability. The controls are defined as follows: COMP refers compensation; ORDVAL stands for order value; PRIORCOMPL refers to prior complaints; FIRSTORD indicates firstorder-flag; GEND refers to gender.
The results of the regression analysis are displayed in Table 2. Since we have chosen a log-log method all coefficients represent elasticities that can be interpreted in line with pricing elasticities common in standard economic theory [26]. Our main hypothesis $\mathrm{H} 1$ is supported. High firm controllability is related to a more negative change in customer purchase behavior compared to low firm controllability $(-.06, \mathrm{p}<.001)$. Keeping all other variables constant, we can infer that the expected percentage change in geometric mean when switching from low controllability service failure to high controllability service failure is $-5.54 \%$ [71].

In Model 2, we add the main effect of RS and the corresponding interaction effect to the model. Our regression model follows the same logic as model 1. RELSTR stands for relationship strength. All other variables as well as the sample remain the same.

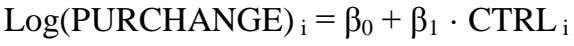

$$
\begin{aligned}
& +\beta_{2} \cdot \log (\text { COMP })_{\mathrm{i}}+\beta_{3} \cdot \log (\text { ORDVAL })_{\mathrm{i}} \\
& +\beta_{4} \cdot \log (\text { PRIORCOMPL })_{\mathrm{i}} \\
& +\beta_{5} \cdot \text { FIRSTORD }_{\mathrm{i}} \\
& +\beta_{6} \cdot \text { GEND }_{\mathrm{i}}+\beta_{7} \cdot \log \left(\text { RELSTR }_{\mathrm{i}}\right. \\
& +\beta_{8} \cdot \mathrm{CTRL}_{\mathrm{i}} \cdot \log \left(\mathrm{RELSTR}_{\mathrm{i}}+\varepsilon_{\mathrm{i}}\right.
\end{aligned}
$$

Table 2 again shows the results. When analyzing the interaction effect of RS we find that RS has a positive moderating effect on the relation between firm controllability and change in consumer purchase behavior $(.03, \mathrm{p}<.05)$.

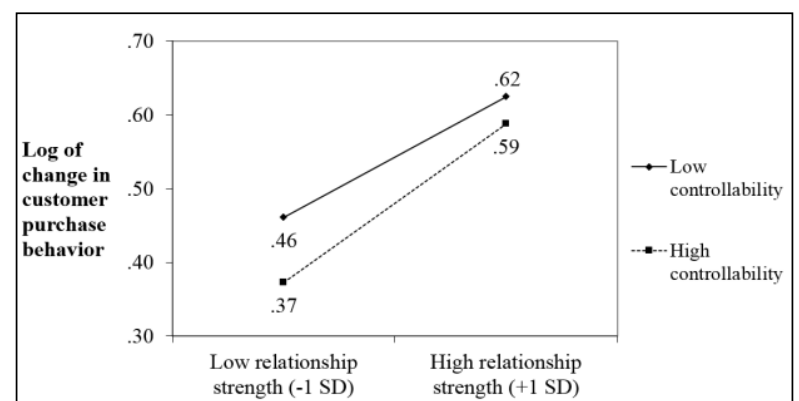

\section{Figure 2. Results for interaction effect of controllability and relationship strength}

In order to understand this effect and to be able to accept or reject our proposed hypotheses we have to analyze the interaction term in more detail. Following an approach recommended by Cohen and Cohen [15] and also used in leading publications in this field [27], we plot the relationship between firm controllability and RS (figure 2). We assess the effect of RS at values of “-1 SD” and "+1 SD”. For controllability we work with the binary coding of 0 for low firm controllability and 1 for high firm controllability. In a low firm controllability context, customers with high RS 
Table 2. Regression results for main effect and interaction effect

\begin{tabular}{|c|c|c|c|c|c|}
\hline \multirow{2}{*}{ Variable } & \multicolumn{2}{|c|}{ Model 1: Main effect } & \multicolumn{3}{|c|}{ Model 2: Interaction effect } \\
\hline & $\beta$ & & & $\beta$ & \\
\hline Intercept $\left(\beta_{0}\right)$ & $.55 * * *$ & $(.01)$ & .54 & $* * *$ & $(.01)$ \\
\hline Controllability $\left(\beta_{1}\right)$ & $-.06 * * *$ & $(.01)$ & -.06 & $* * *$ & $(.01)$ \\
\hline LogCompensation $\left(\beta_{2}\right)$ & $.02 * * *$ & $(.00)$ & .02 & $* * *$ & $(.00)$ \\
\hline LogOrder value $\left(\beta_{3}\right)$ & $-.04 * * *$ & $(.00)$ & -.05 & $* * *$ & $(.00)$ \\
\hline LogPrior complaints $\left(\beta_{4}\right)$ & -.00 & $(.00)$ & -.06 & $* * *$ & $(.01)$ \\
\hline First order flag $\left(\beta_{5}\right)$ & $-.12 * * *$ & $(.01)$ & -.02 & & $(.02)$ \\
\hline Gender $\left(\beta_{6}\right)$ & $.04 * * *$ & $(.01)$ & .02 & $*$ & $(.01)$ \\
\hline LogRelationship strength $\left(\beta_{7}\right)$ & & & .08 & $* * *$ & $(.01)$ \\
\hline Controllability $*$ LogRelationship strength $\left(\beta_{8}\right)$ & & & .03 & $*$ & $(.01)$ \\
\hline
\end{tabular}

.$=\mathrm{p}<.1 ; *=\mathrm{p}<.05 ; * *=\mathrm{p}<.01 ; * * *=\mathrm{p}<.001$. Notes: For Controllability, low controllability is selected as reference category. For First order flag, already existing customers is selected as reference category. For Gender, male is selected as reference category. Huber-White robust standard errors in parentheses.

experience a more positive change in consumer behavior than do customers with low RS (.46 for low RS versus .62 for RS). This supports the "love is blind" effect stated in H2. In a high firm controllability context, we observe the same directional effect (.37 for low RS versus .59 for high RS). This result is in contrast to $\mathrm{H} 3$ and the "love becomes hate" effect. We do not find that customers with a strong relationship to the retailer feel betrayed in case of a complaint characterized by high firm controllability. Instead, customers with a better relationship seem to be loyal to the retailer and show the same "love is blind" effect independently of the controllability level.

We conduct a simple slope test to assess if the relationship is significant and if high RS customers in both controllability scenarios show a significantly more positive change in purchase behavior than do low RS customers [18]. Our analysis confirms that the "love is blind" effect is significant for both the low controllability $(.08, \mathrm{p}<.001)$ and the high controllability condition $(.11, \mathrm{p}<.001)$.

\section{Discussion}

\subsection{Theoretical implications}

Our research adds new findings about the relevance of attribution theory as well as the importance of customer relationship strength. While attribution theory is a well-established theoretical foundation, researchers so far have only provided limited insights regarding its validity for actual consumer purchase behavior. This is surprising given the weak link between stated intentions and actual behavior [12]. We take advantage of a unique field data set provided by a leading European e-commerce retailer to address this question. Our research provides support for our hypothesis 1 that there is a significant negative relation between high firm controllability and change in consumer purchase behavior. Customers who experience a service failure that is characterized by high firm controllability are more likely to decrease their shopping expenditures afterwards compared to customers who experience a non-controllable failure. These findings support the relevance of attribution theory for predicting consumer behavior.

A further ambition of our research is to investigate the role of relationship strength in case of service failures. Researchers so far have reported contradicting results. Some support the "love becomes hate" effect $[28,29]$ while other studies confirm the "love is blind" effect [27, 49]. Our results show that in low as well as in high controllability situations, customers with a strong relationship react significantly less negatively to a service failure. This supports our hypothesis 2 and the "love is blind" effect. Hypothesis 3 and the "love becomes hate" effect is not supported. Grégoire and Fisher [27] argue that potentially only high RS customers who have experienced a series of service failures turn against the company. We controlled for complaint history in our model, therefore, this impact factor should be accounted for. Another explanation could be that only extremely loyal and emotionally committed customers perceive strong feelings of betrayal that are required for the "love becomes hate" effect. We included relationship strength measured by the number of previous orders in our analysis. However, to assess a customer's emotional connection in more detail customer-survey data is required. Moreover, the fashion business is mostly a low 
involvement industry and the retailer in our study has very generous return policies associated with no cost and limited required effort for the customer. Thus, the consequences of the service failure for the customer are not too irritating. Future research should investigate the role of controllability attributions and customer relationship strength in service failure settings where implications for customers are graver and may thus lead to more extreme reactions [23, 70].

\subsection{Managerial implications}

Previous research has shown that service failures can have damaging consequences for companies [43, $63,73]$. Thus, it is critical for managers to understand how different service failures impact customer behavior and what potential measures can be taken to mitigate the negative effects and retain customers. Our results provide valuable guidance for managers.

We find that customers demonstrate significantly more negative reactions to service failures that the company is responsible for. Consequently, firms should prioritize resolving service failures that are perceived as within their control. While it is difficult for companies to reduce or even eliminate service failures in their daily operations, they can adapt their communication strategies to customers. In cases where the company is not responsible for the failure, a firm's communication to its customers should clearly emphasize the external factors causing the service failure. By proactively communicating in service failure situations, a company can further prevent the customer from drawing wrong conclusions regarding controllability. As a result, effective firm communication can lower customers' perceived levels of firm controllability thereby leading to less negative reactions to service failures. This is in line with van Vaerenbergh et al. [65] who also recommend a fast, clear, and proactive communication style.

In addition, our research confirms the importance of strong customer relationships. Most researchers so far have supported the positive implications of strong customer relationships [34, 53, 72]. We extend these findings to the service failure context by assessing the moderating role of relationship strength under different controllability conditions. We find that independently of firm controllability, customers with a strong relationship to the firm react less negatively. In high controllability conditions $\mathrm{RS}$ has an even greater influence which implies that good customer relationships are especially valuable if the company is responsible for a service failure. This emphasizes the need for managers to invest in building and maintaining good customer relationships as they can act as a buffer in difficult times.

\section{Limitations and directions for future research}

By using field data for our research we address multiple research calls that have been asking for nonsurvey based studies [27, 50, 54]. While our approach allows us to draw highly relevant conclusions for theory and practice, there are some limitations and avenues for further research linked to it. We assess relationship strength based on transactional data and are not able to include the customer's perceived relationship strength in our analysis. This bears the risk that a customer's commitment and loyalty are not appropriately reflected in the purchase history. It would be insightful to combine secondary transactional data with survey-based information on a customer's attitude towards and relationship with the company. Further, as indicated earlier, it would be interesting to extend our research to other industries that are characterized by higher levels of involvement or to service failures with more severe consequences. Additionally, we were only able to include compensation as a control measured as the percentage value of a coupon provided to some customers. It would be highly relevant to also include customers' satisfaction with the complaint handling in the analysis to understand if the "love is blind" effect confirmed by our research still holds true if the complaint is not handled well by the service provider. Given the increasing globalization of businesses and the varying importance of personal relationships across the world, it would further be interesting to compare customer reactions to service failures across different markets.

\section{References}

[1] Aaker, J., Fournier, S., and Brasel, S.A. When Good Brands Do Bad. Journal of Consumer Research 31, June (2004), 1-16.

[2] Ahluwalia, R. How Prevalent Is the Negativity Effect in Consumer Environments? Journal of Consumer Research 29, September (2002), 270-279.

[3] Ahluwalia, R., Burnkrant, R.E., and Unnava, H.R. Consumer Response to Negative Publicity: The Moderating Role of Commitment. Journal of Marketing Research 37, May (2000), 203-214.

[4] Anderson, R.E. Consumer Dissatisfaction: The Effect of Disconfirmed Expectancy on Perceived Product Performance. Journal of Marketing Research 10, 1 (1973), $38-44$.

[5] Barnes, B.R., Leonidou, L.C., Siu, N.Y.M., and Leonidou, C.N. Interpersonal Factors as Drivers of Quality and Performance in Western-Hong Kong Interorganizational Business Relationships. Journal of International Marketing 23, 1 (2015), 23-49.

[6] Bendapudi, N. and Berry, L.L. Customers' Motivations 
for Maintaining Relationships With Service Providers. Journal of Retailing 73, 1 (1997), 15-37.

[7] Berry, L.L. Relationship Marketing of Services Growing Interest, Emerging Perspectives. Journal of the Academy of Marketing Science 23, 4 (1995), 236-245.

[8] Breusch, T.S. and Pagan, A.R. A Simple Test for Heteroscedasticity and Random Coefficient Variation. Econometrica 47, 5 (1979), 1287-1294.

[9] Brockner, J., Tyler, T.R., and Cooper-Schneider, R. The Influence of Prior Commitment to an Institution on Reactions to Perceived Unfairness: The Higher They Are, the Harder They Fall. Administrative Science Quarterly 37, 2 (1992), 241-261.

[10] Cambra-Fierro, J., Melero, I., and Sese, F.J. Managing Complaints to Improve Customer Profitability. Journal of Retailing 91, 1 (2015), 109-124.

[11] De Cannière, M.H., De Pelsmacker, P., and Geuens, M. Relationship Quality and Purchase Intention and Behavior: The Moderating Impact of Relationship Strength. Journal of Business and Psychology 25, 1 (2010), 87-98.

[12] Chandon, P., Morwitz, V.G., and Reinartz, W.J. Do Intentions Really Predict Behavior? Self-Generated Validity Effects in Survey Research. Journal of Marketing 69, April (2005), 1-14.

[13] Choi, S. and Mattila, A.S. Perceived controllability and service expectations: Influences on customer reactions following service failure. Journal of Business Research 61, 1 (2008), 24-30.

[14] Clemons, E.K., Gao, G., and Hitt, L.M. When Online Reviews Meet Hyperdifferentiation: A Study of Craft Beer Industry. Journal of Management Information Systems 23, 2 (2006), 149-171.

[15] Cohen, J. and Cohen, P. Applied Multiple Regression/ Correlation Analysis for the Behavioral Sciences. Lawrence Erlbaum Associates, Hillsdale, NJ, 1983.

[16] Crosby, L.A., Evans, K.R., and Cowles, D. Relationship Quality in Services Selling: An Interpersonal Influence Perspective. Journal of Marketing 54, 3 (1990), 68-81.

[17] Dawes, J. The Effect of Service Price Increases on Customer Retention: The Moderating Role of Customer Tenure and Relationship Breadth. Journal of Service Research 11, 3 (2009), 232-245.

[18] Dawson, J.F. Moderation in Management Research: What, Why, When, and How. Journal of Business and Psychology 29, 1 (2014), 1-19.

[19] Festinger, L. A Theory of Cognitive Dissonance. Stanford University Press, Stanford, CA, 1957.

[20] Folkes, V.S. Consumer Reactions to Product Failure: An Attributional Approach. Journal of Consumer Research 10, 4 (1984), 398-409.

[21] Folkes, V.S. Recent Attribution Research in Consumer Behavior: A Review and New Directions. Journal of Consumer Research 14, 4 (1988), 548-565.

[22] Folkes, V.S., Koletsky, S., and Graham, J.L. A Field Study of Causal Inferences and Consumer Reaction: The View from the Airport. Journal of Consumer Research 13, 4 (1987), 534-539.

[23] Freedman, J.L. Involvement, Discrepancy, and Change. Journal of Abnormal and Social Psychology 69, 3 (1964), 290-295.

[24] Goodman, P.S., Fichman, M., Lerch, J.F., and Synder,
P.R. Customer-Firm Relationships, Involvement, and Customer Satisfaction. Academy of Management Journal 38, 5 (1995), 1310-1324.

[25] Goudarzi, K., Borges, A., and Chebat, J.C. Should retailers pay to bring customers back? The impact of quick response and coupons on purchase outcomes. Journal of Business Research 66, 5 (2013), 665-669.

[26] Granados, N., Gupta, A., and Kauffman, R.J. Online and Offline Demand and Price Elasticities: Evidence from the Air Travel Industry. Information Systems Research 23, 1 (2012), 164-181.

[27] Grégoire, Y. and Fisher, R.J. The effects of relationship quality on customer retaliation. Marketing Letters 17, 1 (2006), 31-46.

[28] Grégoire, Y. and Fisher, R.J. Customer betrayal and retaliation: when your best customers become your worst enemies. Journal of the Academy of Marketing Science 36, 2 (2008), 247-261.

[29] Grégoire, Y., Tripp, T.M., and Legoux, R. When Customer Love Turns into Lasting Hate: The Effects of Relationship Strength and Time on Customer Revenge and Avoidance. Journal of Marketing 73, 6 (2009), 18-32.

[30] Grüschow, R., Kemper, J., and Brettel, M. Do Transaction Costs of Payment Systems Differ Across Customers in E-Commerce? ECIS 2015 Proceedings, (2015), $1-18$.

[31] Hair, J.F., Black, W.C., Babin, B.J., and Anderson, R.E. Multivariate Data Analysis. Pearson, Harlow, 2009.

[32] Hansen, K. and Singh, V. Are Store-Brand Buyers Store Loyal? An Empirical Investigation. Management Science 54, 10 (2008), 1828-1834.

[33] Heider, F. The Psychology of Interpersonal Relations. John Wiley, New York, 1958.

[34] Hennig-Thurau, T. and Klee, A. The Impact of Customer Satisfaction and Relationship Quality on Customer Retention: A Critical Reassessment and Model Development. Psychology \& Marketing 14, 8 (1997), 737-764.

[35] Herr, P.M., Kardes, F.R., and Kim, J. Effects of Wordof-Mouth and Product-Attribute Information on Persuasion: An Accessibilty-Diagnosticity Perspective. Journal of Consumer Research 17, 4 (1991), 454-462.

[36] Hess, R.L. The impact of firm reputation and failure severity on customers' responses to service failures. Journal of Services Marketing 22, 5 (2008), 385-398.

[37] Hess, R.L., Ganesan, S., and Klein, N.M. Service Failure and Recovery: The Impact of Relationship Factors on Customer Satisfaction. Journal of the Academy of Marketing Science 31, 2 (2003), 127-145.

[38] Hess, R.L., Ganesan, S., and Klein, N.M. Interactional service failures in a pseudorelationship: The role of organizational attributions. Journal of Retailing 83, 1 (2007), 79-95.

[39] Hewett, K. and Krasnikov, A. V. Investing in BuyerSeller Relationships in Transitional Markets: A MarketBased Assets Perspective. Journal of International Marketing 24, 1 (2016), 57-81.

[40] Homburg, C., Fürst, A., and Koschate, N. On the importance of complaint handling design: a multi-level analysis of the impact in specific complaint situations. Journal of the Academy of Marketing Science 38, 3 (2010), 265-287. 
[41] Hur, J. and Jang, S. Toward service recovery strategies: the role of consumer-organization relationship norms. Journal of Services Marketing 30, 7 (2016), 724-735.

[42] Kaltcheva, V.D., Winsor, R.D., and Parasuraman, A. Do customer relationships mitigate or amplify failure responses? Journal of Business Research 66, 4 (2013), 525-532.

[43] Keaveney, S.M. Customer Switching Behavior in Service Industries: An Exploratory Study. Journal of Marketing 59, 2 (1995), 71-82.

[44] Kennedy, P. A Guide to Econometrics. WileyBlackwell, Malden, MA, 2008.

[45] Kim, N. and Ulgado, F.M. The effect of on-the-spot versus delayed compensation: the moderating role of failure severity. Journal of Services Marketing 26, 3 (2012), 158167.

[46] Knox, G. and van Oest, R. Customer Complaints and Recovery Effectiveness: A Customer Base Approach. Journal of Marketing 78, 5 (2014), 42-57.

[47] Lind, E.A. and Earley, P.C. Procedural Justice and Culture. International Journal of Psychology 27, 2 (1992), 227-242.

[48] Magnini, V.P., Ford, J.B., Markowski, E.P., and Honeycutt, E.D.J. The service recovery paradox: justifiable theory or smoldering myth? Journal of Services Marketing 21, 3 (2007), 213-225.

[49] Mattila, A.S. The Impact of Relationship Type on Customer Loyalty in a Context of Service Failures. Journal of Service Research 4, 2 (2001), 91-101.

[50] Mattila, A.S. The impact of service failures on customer loyalty: The moderating role of affective commitment. International Journal of Service Industry Management 15, 2 (2004), 134-149.

[51] Maxham, J.G. Service recovery's influence on consumer satisfaction, positive word-of-mouth, and purchase intentions. Journal of Business Research 54, 1 (2001), 11-24. [52] McColl-Kennedy, J.R., Daus, C.S., and Sparks, B.A. The Role of Gender in Reactions to Service Failure and Recovery. Journal of Service Research 6, 1 (2003), 66-82.

[53] Morgan, R.M. and Hunt, S.D. The Commitment-Trust Theory of Relationship Marketing. Journal of Marketing 58, 3 (1994), 20-38.

[54] Parasuraman, A. Modeling Opportunities in Service Recovery and Customer-Managed Interactions. Marketing Science 25, 6 (2006), 590-593.

[55] Pick, D., Thomas, J.S., Tillmanns, S., and Krafft, M. Customer win-back: the role of attributions and perceptions in customers' willingness to return. Journal of the Academy of Marketing Science 44, 2 (2016), 218-240.

[56] Reinartz, W.J. and Kumar, V. On the Profitability of Long-Life Customers in a Noncontractual Setting: An Empirical Investigation and Implications for Marketing. Journal of Marketing 64, 4 (2000), 17-35.

[57] Roggeveen, A.L., Grewal, D., Townsend, C., and Krishnan, R. The Impact of Dynamic Presentation Format on Consumer Preferences for Hedonic Products and Services. Journal of Marketing 79, 6 (2015), 34-49.

[58] Sabharwal, N., Soch, H., and Kaur, H. Are We Satisfied with Incompetent Services? A Scale Development Approach for Service Recovery. Journal of Services Research 10, 1 (2010), 125-142.

[59] Sheth, J.N. and Parvatlyar, A. Relationship Marketing in
Consumer Markets: Antecedents and Consequences. Journal of the Academy of Marketing Science 23, 4 (1995), 255-271. [60] Skowronski, J.J. and Carlston, D.E. Social Judgment and Social Memory: The Role of Cue Diagnosticity in Negativity, Positivity, and Extremity Biases. Journal of Personality and Social Psychology 52, 4 (1987), 689-699.

[61] Smith, A.K., Bolton, R.N., and Wagner, J. A Model of Customer Satisfaction with Service Encounters Involving Failure and Recovery. Journal of Marketing Research 36, 3 (1999), 356-372.

[62] Storbacka, K., Strandvik, T., and Grönroos, C. Managing Customer Relationships for Profit: The Dynamics of Relationship Quality. International Journal of Service Industry Management 5, 5 (1994), 21-38.

[63] Surachartkumtonkun, J., Patterson, P.G., and McCollKennedy, J.R. Customer Rage Back-Story: Linking NeedsBased Cognitive Appraisal to Service Failure Type. Journal of Retailing 89, 1 (2013), 72-87.

[64] Tax, S.S., Brown, S.W., and Chandrashekaran, M. Customer Evaluations of Service Complaint Experiences: Implications for Relationship Marketing. Journal of Marketing 62, 2 (1998), 60-76.

[65] Van Vaerenbergh, Y., Orsingher, C., Vermeir, I., and Larivière, B. A Meta-Analysis of Relationships Linking Service Failure Attributions to Customer Outcomes. Journal of Service Research 17, 4 (2014), 1-18.

[66] Ward, J.C. and Ostrom, A.L. Complaining to the Masses: The Role of Protest Framing in Customer-Created Complaint Web Sites. Journal of Consumer Research 33, 2 (2006), 220-230.

[67] Weiner, B. An Attributional Theory of Achievement Motivation and Emotion. Psychological Review 92, 4 (1985), 548-573.

[68] Weiner, B. Attributional Thoughts about Consumer Behavior. Journal of Consumer Research 27, 3 (2000), 382387.

[69] Wirtz, J. and Mattila, A.S. Consumer responses to compensation, speed of recovery and apology after a service failure. International Journal of Service Industry Management 15, 2 (2004), 150-166.

[70] Wong, N.Y. The role of culture in the perception of service recovery. Journal of Business Research 57, 9 (2004), 957-963.

[71] Woolridge, J.M. Introductory Econometrics: A Modern Approach. South-Western, Cengage Learning, Mason, $\mathrm{OH}$, 2013.

[72] De Wulf, K., Odekerken-Schröder, G., and Iacobucci, D. Investments in Consumer Relationships: A Cross-Country and Cross-Industry Exploration. Journal of Marketing 65, 4 (2001), 33-50.

[73] Zeelenberg, M. and Pieters, R. Beyond valence in customer dissatisfaction: A review and new findings on behavioral responses to regret and disappointment in failed services. Journal of Business Research 57, 4 (2004), 445455.

[74] Zhang, R., Li, G., Wang, Z., and Wang, H. Relationship value based on customer equity influences on online groupbuying customer loyalty. Journal of Business Research 69, 9 (2016), 3820-3826. 